decision making and not a substitute for it.

Part of the reason for the growing anxiety about risk is obvious enough modern technology holds out great promise but it carries with it potential for danger. Its benefits and hazards are not equally distributed. Nor is exposure to risk always within the control of the individual, who may choose not to smoke, but has little say in the disposal of toxic waste.

The importance of both books is to emphasize that rational decisions on risk cannot be reduced largely to a calculus of probabilities. Such an approach would simply brush under the carpet the inescapable political dimensions of many such decisions. But worse, it fails to account for the ways in which reasonable and rational beings in fact seek to cope with the complexities of how to act in the face of potential danger.

S.F. Cotgrove is Professor of Sociology at the University of Bath.

\title{
Dendrochronology by numbers
}

\section{John Fletcher}

Tree-Ring Dating and Archaeology. By M.G.L. Baillie. Pp.274. ISBN UK 0-7099-0613-7; ISBN US 0-226-03630-8. (Croom Helm/University of Chicago Press: 1982.) £16.95, \$25.

THE attraction of using tree-rings for dating buildings and archaeological artefacts lies in the high accuracy - to the year or to within a decade - that can be achieved if the felling date of the timber can be identified. But how often is that feasible? One limitation lies in the relatively few species which have annual growth that can be reliably identified and converted to a chronology. Another is that in temperate areas various ecological factors affect the growth rings of each species, so a range of reference chronologies may be necessary to permit a large fraction of the somewhat different ringwidth patterns to be matched. In addition, palaeoclimatologists recognize from climatic swings in the past that the extent of dendroecological zones has not remained constant.

Artefacts from extreme environments are especially suitable for tree-ring dating as stress comes mainly from one factor. Douglass in 1929 was the first to use this to advantage and date ancient cliff dwellings in Arizona and New Mexico from the pines used in building them. In central Europe, first Huber then Hollstein had by the mid-1960s matched sequences of rings from several hundreds of the oaks used in buildings and artefacts in hilly areas, including prehistoric lakeside settlements around the Alps.

In contrast, the diverse stresses which apply to valley and lowland oaks in northwest Europe made the pattern matching of rings impossible in the pre-computer era. In this book Dr Baillie tells of his success, using a computer program devised with his colleague J.R. Pilcher and now widely adopted, in matching Irish samples and a few from south-west Scotland. Archaeological remains of oak are scarce in Ireland, and the items dated number only about thirty. They include cruck houses, the Dublin waterfront, lake dwellings known as crannogs and the archaeologically interesting horizontal water-mills. The results have enabled Baillie to construct two oak chronologies for the last two millennia (that for fossil timber for carbon-14 calibration goes back much further).

The methodology described is iargely that of the Tucson tree-ring laboratory in which ring-widths are converted to indices, thus losing, when plotted, visual features known as indicator years and signatures. (As applied elsewhere in Europe these features are of particular value, for example in matching short sequences with dates known approximately by other evidence.) The author's approach is largely statistical and he displays no interest in the scientific and analytical research which has revealed relevant information about wood structure and tree physiology. Thus the value of a rare abnormality in oak, noticed by Buffon as of chronological significance, is not mentioned.

The book gives a detailed, step-by-step account of the regional application of the author's method to a limited number of widely separated items in the wetter zone which covers much of the western part of the British Isles. As such it will be of interest to departmental libraries and to the enquiring archaeologist. It is not suitable for use as a text-book, however. Some statements are misleading in the context of European dendrochronology, while inaccuracies render parts unsuitable for being quoted. This applies in particular when the author turns from Ireland to write briefly about southern Britain. In this region, not only oak trees but oak artefacts and excavated material are numerous. In the lower and drier zone - which includes rain shadows in the midlands, the east and south-east of England, as well as continental areas around the southern basin of the North Sea - the Irish chronologies rarely apply (and vice versa) while Baillie's method is too limited for success in matching a high proportion of samples.

John Fletcher is at the Research Laboratory for Archaeology and the History of Art, University of Oxford.

\section{Course of storms}

\section{T. N. Krishnamurti}

Tropical Cyclones: Their Evolution, Structure and Effects. By Richard A. Anthes. Pp.208. ISBN 0-933876-8. (American Meteorological Society, Boston: 1982.) $\$ 40$.

IN TEACHING tropical meteorology courses it is generally necessary to devote about 25 per cent of the course to tropical cyclones: their origin, maintenance and eventual decay. Richard Anthes has provided, for my needs, an important text that covers this area more than adequately.

The monograph deals with the structure, life cycle, physical effects, numerical simulation, storm modification, oceanic responses and weather forecasting aspects of tropical cyclones. The description of structure is based on the best available observations of such storms, mostly provided by the National Hurricane Center in the United States. In the area of physical effects the role of cumulus convection is brought out in considerable depth, and a critical appraisal of the convective heating, the vertical eddy flux of heat, the role of non-convective heating, convergence of eddy flux of moisture and the moistening by cumulus scale motions is presented neatly and clearly. In this area, Anthes discusses a number of recent findings, most notably the role of radiative forcing in the diurnal modulation of tropical cyclones. His breakdown deals with observational as well as modelling aspects, and will be most helpful to students modelling such storms.

The account of modelling covers the state of the art of simulation of idealized as well as real data numerical weather prediction experiments in two and three dimensions. Several examples carry important information on why storms form from incipient disturbances in some cases and not in others; this is largely based on Anthes' own research over many years. The oceanic response is a topic hardly addressed in most other texts or reviews, and is a welcome addition to the completeness of this book. The noteworthy area here is the role of the oceanic stratification.

The final section covers the use of statistical and dynamical methods in operational prediction up to three days from the initial state. Here Anthes summarizes the current ranges for the error statistics in hurricane (typhoon) prediction centres in the United States and elsewhere.

I find this an extremely important book with few areas to dispute in the assessment of our current understanding of hurricanes. No previous text has addressed the wide range of teaching needs covering both observations and theory. It is a blend that is remarkably well done in this monograph.

T.N. Krishnamurti is a Professor in the Department of Meteorology at The Florida State University, Tallahassee. 